\title{
Impact of urinary incontinence on quality of Life of women in a community sample in three districts of Sri Lanka - A cross sectional study
}

Pathiraja RPa, Prathapen $S^{b}$, Gunewardena $S^{c}$

\begin{abstract}
Wellbeing of a person includes a good quality of life (QOL), which can be perceived and mediated by a many factors. Although UI has no impact on mortality it is one of the conditions that can significantly affect a person's QOL. This paper aims to investigate the impact of UI on the women's QOL.
\end{abstract}

Methods: This study is a community based cross-sectional study performed in three districts of Sri Lanka targetting the population of women who were above 18 years of age. A sample of 2310 women was selected for this study in cluster basis. A cluster was a Public Health Midwife area, and from each cluster 15 women were selected. An interviewer administered questionnaire consisting of sociodemographic factors, medical and Obstetric history, and the King's Health Questionnaire (KHQ) was used. A trend test, Jonckheere-Terpstra test was performed and significance was set at $5 \%$.

Results: Majority of the women in all three districts felt that felt that UI had no impact on their general health. QOL showed an impact on the trend of severity on stress incontinence and on the severity trend on urge incontinence, which was statistically significant with each domain namely role limitations, physical limitations, social limitations, personal relationships, emotional problems and sleep/energy issues. Coping strategies like wear sanitary pads to avoid getting wet with urine $(5.4 \%)$, limiting their fluid intake at all times $(11 \%)$ were also observed.

Conclusions: The negative effect of UI on QOL needs to be addressed targeting those at higher risk. Awareness on treatment needs to be addressed, as all QOL domains were affected by UI.

Key words: urinary incontinence, quality of life

a Professor of Obstetrics and Gynaecology, Department of Obstetrics and Gynaecology, University of Sri Jayewardenepura, Sri Lanka

${ }^{b}$ Senior Lecturer, Department of Community Medicine, University of Sri Jayewardenepura, Sri Lanka

'Senior Lecturer, Department of Community Medicine, University of Sri Jayewardenepura, Sri Lanka.

Correspondence: Prof. R. P. Pathiraja MBBS $M S$ FRCOG FSLOG

Email - ramya_pathiraja@sjp.ac.lk

(D) http:// orcid.org/0000-0002-3673-4466

Competing interests: The authors report no conflict of interest
Sufferers give up many aspects of their usual lifestyle with obvious detriment to their careers, and psychological wellbeing 5 . Shame, concern about leakage, and odour can impair a woman's ability to participate in employment and domestic responsibilities, restrict social contacts and limit interpersonal and sexual relationships ${ }^{6,7}$. A new way of life develops and they find their own ways to cope, avoiding social and physical activities, limiting fluid intake, visiting the toilet frequently, and wearing protective pads or cloth ${ }^{6,89}$. These will ultimately result in depression, anxiety, poor life satisfaction and impaired quality of life.

Quality of life (QoL) is an individual's perceived level of physical, psychological, and social wellbeing. It is mediated by personal and cultural values and beliefs, self-concepts, goals, and life expectancy. The term is influenced by a broad spectrum of human experiences including diseases, accidents, treatments, interpersonal relationships, and social support ${ }^{2}$. Clinicians'and patients' judgments of quality of life differ considerably, leading to differing perceptions of the effects of clinical interventions ${ }^{10}$. The patient's opinion is therefore becoming recognized as central to the assessment of disease severity and the effects of treatment.

Reasons for delay in seeking care are unknown. A combination of factors including under reporting by patients and under recognition as a significant clinical problem by health providers, and socio-cultural factors, specially in certain geographical areas play a major role ${ }^{11,12,13}$.

The condition goes unreported and many sufferers are reluctant to discuss their condition with their healthcare provider or family members, because of embarrassment associated with the dysfunction ${ }^{14}$. Disappointingly, although incontinence is the source of considerable 
morbidity, over $50 \%$ of incontinent women never seek help for their condition or do so only after many years of misery ${ }^{15}$. Equally health care providers fail to discuss urinary problems with their patients. As a result, UI remains underreported, despite increased awareness and improved diagnosis and treatment ${ }^{16}$.

Very few cross-country studies carried out in Sri Lanka with the purpose of determining the QOL of sufferers, led us to conduct this community-based crosssectional study to investigate the impact of UI on the women's QOL.

\section{METHODOLOGY}

This study is a community based crosssectional study. Out of the 24 districts in Sri Lanka, three districts; Colombo, Ratnapura and Trincomalee, were selected for this study as the women in these three districts would represent the Sri Lankan female population as per ethnicity and religion and also as these districts would encapsulate the urban, riral and the estate population. The initial hypothesis was that through this population we could access a very large part of the female population of our country. We believe that the distinctive characteristics of these three districts allow us, to a very considerable extent, to extrapolate the results of our sample to the majority of the general female population.

The targeted population was the female population over 18 years. Among the three districts, this study population were stratified into three age groups; 18-35 years, $36-50$ years and 51 years and above, as it is known that the QOL of urinary incontinence differs with age ${ }^{17}$. Women who had genito-urinary surgery were excluded. The QOL of women with urinary incontinence in Sri Lanka is unknown. Therefore, assuming 50\% of women having good QOL with urinary incontinence in a particular age category and for a maxiumum sample size, with $5 \%$ precision, a sample size of 384 was obtained from each age group ${ }^{18}$. The sample size was multiplied by $1.5^{19}$, which is the design effect since the sampling method was a cluster sampling. A sample size of 675 was obtained from each age category with a total of 2025 women. Expecting a $15 \%$ non reponse rate a total sample of 2310 women was selected for this study.

Three Medical officer of Health (MOH) areas, which are the basic Health unit araes in Sri Lanka, were randomly selected from each three selected districts. From each $\mathrm{MOH}$ areas, 5 Public Health Midwives (PHM) areas were further randomly selected. These PHM areas were considered as clusters. Within a cluster a house hold was randomly selected continuing onto every other household on that street. In each household, all women in the three age categories were selected until the sample size was achieved. In each age category, in a PHM area 15 women were selected.

UI was defined as any involuntary loss of urine. Stress urinary incontinence (SUI) symptoms were defined as loss of urine caused by sneezing, coughing, exercising, lifting or physical activity. Urge urinary incontinence (UUI) symptoms were defined as a sudden urge to void with subsequent leakage. MUI symptoms were defined as women who had at least one stress and one urge symptom ${ }^{20}$. Women who did not have any of these symptoms were considered continent. We collected this information with help of symptom questionnaire.

When defining the impact of UI, the frequency of occurrence is taken into consideration. UI occurrence was considered mild if it occurred once or twice a week, moderate if it was once or twice a day and severe if it was 3 or more times a day. The degree of the impact of incontinence was determined by taking the following into consideration. The necessity and the frequency to wear perineal pads, to restrict fluid intake, to change under clothes when they become wet, worry in a situation of smell, embarrassment and being unable to wear ordinary clothes.

An interviewer administered questionnaire (IAQ) was used as the data collection instrument. This IAQ consists of three parts; Sociodemographic factors, medical and Obstetric History, and the King's Health Questionnaire (KHQ), which consists of questions on Quality of Life of Women with Urinary Incontinence. The KHQ is a validated questionnaire and with high reliability ${ }^{21}$. The KHQ is a disease-specific QOL instrument for UI, comprising of general health perceptions with six multi-item domains which include role limitations, physical limitations, social limitations, personal relationships, emotional problems and sleep/energy issues. The KHQ was judgmentally validated by gynecologists in Sri Lanka and later translated to Sinhala and Tamil which was then back translated to English. Any discrepancies in the translation was again corrected. The translated questionnaire was pilot tested at an area that was not in the data collection area in Sri Lanka. Pre testing were done in a small group of women $(n=50)$ in Borelesgamuwa $\mathrm{MOH}$ area and after reviewing these preliminary results, some questions were revised resulting in an improved, final version.

The questionnaire was printed in three different languages Sinhala, Tamil and English with 27 questions presented in seven different domains, with a separate scale for measurement of the severity of urinary symptoms. It is expected that items forming a domain should contribute independently to the overall score in that domain. We used a four-point scoring system for each of the item. Each of the domains to be scored out of the same total and therefore each contributes similarly to the overall questionnaire score. Scores in each domain range between zero and 100 , a higher score indicating a greater impairment of quality of life.

Medical conditions such as hypertension, diabetes mellitus, and cardio pulmonary disease were excluded after going through the history and their medical records. The public health midwives were trained to collect data and all subjects were told that participation in the investigation was strictly voluntary. The data was handled only by the investigators and the confidentiality was maintained. All women who were identified to have more than moderate UI interfereing with their QOL were referred to the nearest tertiary hospitals. The research was conducted with the permission of Deputy Provincial Director of Health Services of the three districts and from the relevant MOH's of the districts.

A trend test, Jonckheere-Terpstra test was performed to describe the association between QOL and the impact. Significance was tested at $5 \%$ of signifinace levels. Proportions were used to describe the Incontinence impact and QoL scores were described using means and standard deveiations.

Ethical clearance was obtained from the Ethical Review Committee of the Faculty of Medical Sciences, University of Sri Jayewardenepura. 


\section{RESULTS}

2310 women completely responded to the questions asked. The mean age of the women respondents who participated in the study was $43.8+14.3$ years (range 18 - 90 years). Most women (66.7\%) had more than two or more children. Nearly $78 \%$ had completed secondary education, but with only $13 \%$ being employed. The majority in the study area were Sinhala Buddhist $(65.6 \%)$; the remaining participants, primarily estate workers, were Tamil Hindus.

Majority surveyed women in all three districts felt that felt that UI had no impact on their general health (table 1).

In the second part of the questionnaire, women were asked about the degree of impact of UI and related symptoms on several domains of their QoL: role limitations, physical limitations, social limitations, personal relationships, emotions, sleep and energy. The responses, rated on a four level scale, starting with no impact and progressing to mild, moderate and severe impact, are presented in Table 2. A trend test, Jonckheere-Terpstra test was performed to describe the QoL domains with the severity trend, and a statistically significant trend was shown for higher levels of impact on stress incontinence (from "nil", "mild", "moderate" to "severe" impact of urge incontinence) for all domains.

Similar results were seen with the impact of urge incontinence and the domains of QOL. As per the QoL impact on stress incontinence, urge incontinence also showed statistically significant results when comparing the trend of the urge incontinence with each domain. However the mean average for severity, unlike stress incontinent which was highest for Personal relationships, in case of urge incontinence the highest mean was observed for social limitations.

In addition, the woman's perception of the severity of her incontinence was also measured. Among those with urge incontinence $5.4 \%$ said that they always wear sanitary pads to avoid getting wet with urine, whereas among those with

Table 1. Percentage distribution of patients in the three districts according to impact of urinary incontinence

\begin{tabular}{|l|l|l|l|l|}
\hline \multirow{2}{*}{ Incontinence Impact } & \multicolumn{4}{l|}{ District Frequency (\%) } \\
\cline { 2 - 5 } & Colombo & Ratnapura & Trincomalee & Total \\
\hline No impact & $590(67.1)$ & $532(75.7)$ & $368(50.5)$ & $1490(64.5)$ \\
\hline Mild impact & $190(21.6)$ & $126(17.9)$ & $260(35.7)$ & $576(24.9)$ \\
\hline Moderate impact & $67(7.6)$ & $41(5.8)$ & $87(12.0)$ & $195(8.4)$ \\
\hline Severe impact & $32(3.6)$ & $4(0.6)$ & $13(1.8)$ & $49(2.1)$ \\
\hline Total & $879(100.0)$ & $703(100.0)$ & $728(100.0)$ & $2310(100.0)$ \\
\hline
\end{tabular}

Table 2. Association between Stress Incontinence and QoL scores per King's Health questionnaire domains

\begin{tabular}{|c|c|c|c|c|}
\hline & Degree of il & $t$ of Stress In & inence & \\
\hline & No & Mild & Moderate & Severe \\
\hline Role Limitations $(\mathrm{n}=2238$ ) & & & & \\
\hline Mean \pm SD & $8.4 \pm 19.8$ & $10.1 \pm 19.7$ & $30.7 \pm 26.1$ & $40.6 \pm 26.1$ \\
\hline Jonckheere-Terpstra test (Sig) & $Z=11.06$ & .001 & & \\
\hline Physical limitations $(n=2253)$ & & & & \\
\hline Mean \pm SD & $8.7 \pm 18.2$ & $8.9 \pm 18.9$ & $28.4 \pm 26.4$ & $38.2 \pm 29.7$ \\
\hline Jonckheere-Terpstra test (Sig) & $Z=11.64$ & .001 & & \\
\hline Social limitation $(n=2258)$ & & & & \\
\hline Mean \pm SD & $7.4 \pm 17.1$ & $8.4 \pm 16.7$ & $24.2 \pm 24.9$ & $34.0 \pm 27.3$ \\
\hline Jonckheere-Terpstra test (Sig) & $Z=9.78 ; p$ & & & \\
\hline Personal relationships $(n=2116)$ & & & & \\
\hline Mean \pm SD & $19.9 \pm 18.7$ & $25.3 \pm 19.6$ & $39.4 \pm 25.6$ & $40.7 \pm 26.9$ \\
\hline Jonckheere-Terpstra test (Sig) & $Z=10.25$; & .001 & & \\
\hline Emotions $(n=2238)$ & & & & \\
\hline Mean \pm SD & $4.9 \pm 15.5$ & $5.9 \pm 15.1$ & $19.0 \pm 24.9$ & $21.9 \pm 29.2$ \\
\hline Jonckheere-Terpstra test (Sig) & $\mathrm{Z}=6.9 ; \mathrm{p}$ & & & \\
\hline Sleep and energy $(n=2242)$ & & & & \\
\hline Mean \pm SD & $5.9 \pm 15.7$ & $7.7 \pm 16.6$ & $24.6 \pm 28.1$ & $25.4 \pm 24.2$ \\
\hline Jonckheere-Terpstra test (Sig) & $\mathrm{Z}=7.7 ; \mathrm{p}<$ & & & \\
\hline
\end{tabular}


Table 3. Association between Urge Incontinence and QoL scores per King's Health questionnaire domains

\begin{tabular}{|c|c|c|c|c|}
\hline & Degree of & act of Urge I & tinence & \\
\hline & No & Mild & Moderate & Severe \\
\hline Role Limitations $(\mathrm{n}=2238)$ & & & & \\
\hline Mean \pm SD & $8.8 \pm 21.4$ & $8.9 \pm 19.3$ & $33.8 \pm(17.2$ & $40.6 \pm 26.1$ \\
\hline Jonckheere-Terpstra test (Sig) & $Z=16.6$ & .001 & & \\
\hline Physical limitations $(n=2253)$ & & & & \\
\hline Mean \pm SD & $7.4 \pm 18.2$ & $8.9 \pm 17.4$ & $29.7 \pm 23.4$ & $41.2 \pm 31.7$ \\
\hline Jonckheere-Terpstra test (Sig) & $Z=16.9$ & .001 & & \\
\hline Social limitation $(n=2258)$ & & & & \\
\hline Mean \pm SD & $5.9 \pm 15.5$ & $7.5 \pm 16.4$ & $28.6 \pm(20.1$ & $41.5 \pm 25.9$ \\
\hline Jonckheere-Terpstra test (Sig) & $Z=18.3$ & 001 & & \\
\hline Personal relationships $(\mathrm{n}=2116)$ & & & & \\
\hline Mean \pm SD & $17.4 \pm 20.1$ & $27.6 \pm 17.4$ & $37.2 \pm 22.5$ & $40.2 \pm 26.3$ \\
\hline Jonckheere-Terpstra test (Sig) & $Z=13.8$ & .001 & & \\
\hline Emotions $(n=2238)$ & & & & \\
\hline Mean \pm SD & $4.4 \pm 14.2$ & $4.4 \pm 14.3$ & $20.2 \pm 23.2$ & $31.0 \pm 28.4$ \\
\hline Jonckheere-Terpstra test (Sig) & $Z=13.9$ & .001 & & \\
\hline Sleep and energy $(n=2242)$ & & & & \\
\hline Mean \pm SD & $4.5 \pm 13.5$ & $5.8 \pm 14.0$ & $27.5 \pm 24.8$ & $38.2 \pm 27.5$ \\
\hline Jonckheere-Terpstra test (Sig) & $Z=13.9$ & .001 & & \\
\hline
\end{tabular}

Table 4. Severity of the incontinence and measures used

\begin{tabular}{|c|c|c|c|}
\hline \multirow[t]{2}{*}{ Measures used } & \multicolumn{3}{|c|}{ Incontinence } \\
\hline & Stress $(\%)$ & Urge & Both \\
\hline \multicolumn{4}{|c|}{ Using sanitary pads to avoid getting wet with urine } \\
\hline \multicolumn{4}{|l|}{ Not at all } \\
\hline Sometimes & $185(86.0)$ & $238(67.8)$ & $515(76.2)$ \\
\hline Most of the times & $13(6.0)$ & $68(19.4)$ & $88(13.0)$ \\
\hline \multirow[t]{2}{*}{ Always } & $08(3.7)$ & $26(7.4)$ & $53(7.8)$ \\
\hline & $09(4.2)$ & $19(5.4)$ & $20(3.0)$ \\
\hline \multicolumn{4}{|c|}{ Limiting the fluid intake } \\
\hline Not at all & $177(82.3)$ & $206(58.4)$ & $463(69.0)$ \\
\hline Sometimes & $18(8.4)$ & $60(17.0)$ & $80(11.9)$ \\
\hline Most of the times & $13(6.0)$ & $48(13.6)$ & $61(9.1)$ \\
\hline Always & $07(3.3)$ & $39(11.0)$ & $67(10.0)$ \\
\hline \multicolumn{4}{|c|}{ Changing underwear frequently } \\
\hline Not at all & $160(74.4)$ & $207(58.3)$ & $498(74.8)$ \\
\hline Sometimes & $29(13.5)$ & $80(22.5)$ & $76(11.4)$ \\
\hline Most of the times & $14(6.5)$ & $45(12.7)$ & $68(10.2)$ \\
\hline Always & $12(5.6)$ & $23(6.5)$ & $24(3.6)$ \\
\hline
\end{tabular}


stress incontinence, $86 \%$ do not wear sanitary pads at all. Eleven percent of women with urge incontinence limit their fluid intake at all times whereas those with stress incontinence $82.3 \%$ did not have any intentions of limiting their fluid intake. Change of underwear was always a problem $(6.5 \%)$ in those women with urge incontinence.

In both groups, women with stress incontinence and women with urge incontinence had higher scores in all domains, which were statistically significant. $\quad(\mathrm{P}<0.001) . \quad$ Physical limitations, social imitations, emotions, sleep and energy domains had a significantly higher scores in women with UI in compare to SI and had an overall greater impairment of QoL. QoL was affected negatively in all the domains ( $p$ $<0.001)$.

Perception of severity of urinary incontinence was equal in women in both groups with SI and UI. It was also recognized that as the severity of UI increases, QOL has decreased.

\section{DISCUSSION}

This is the second part of the study; the first part was on the prevalence and risk factors of urinary incontinence and has already been published in the urology journal in March 2017. Compare to other studies, we had a high response rate, due to the fact that questionnaires were completed in the privacy of the women's own homes.

Majority of women surveyed felt that UI had no impact on their general health, which is compatible with some other studies $^{1}$. In our study, even though, the majority of women consider that there is no impact of UI on general health, a significant proportion of the study population had a poor quality life due to SI and UI as reported by Ko et $\mathrm{a}^{22}$. Compare to SI, UI had higher scores not only in physical limitation but also on social limitations, emotions, sleep and energy domains in accordance with previous studies $^{23}$. This is due to the unpredictable nature of the urinary symptoms associated with UI, makes adaptation more difficult, and therefore the impairment of quality of life was greater for these women.

Consistent with the finding by Ozerdogan et $\mathrm{al}^{24}$ QOL decreased with increased severity of UI. Many sufferers of UI, try to manage their symptoms by adjusting to the problem instead of seeking treatment. Of those who discuss their symptoms with their primary care physicians, $30 \%$ do not receive treatment and $80 \%$ are not examined $^{22}$.

In Sri Lanka, we have a good health care system, yet majority of sufferers reluctant to discuss these problems due to shame and embarrassment despite increased awareness and improved diagnosis and treatment. As a result UI remains under reported. Therefore, there is value in raising awareness among women and their health care providers of the possibilities for diagnosing and treating UI.

It is hoped that measurement of quality of life will become a routine part of the assessment of all incontinent women. Dismissing incontinence and its related symptoms not only has a negative impact on the quality of life of those who suffer, but it also puts a considerable financial burden on society, resulting from a failure to properly diagnose and treat UI.

\section{LIMITATIONS}

None of the women had Gynaecological examination or urological investigation and the presence of UI was determined by verbal inquiry alone and this may have reduced the precision of arriving at a diagnosis. This also may be the reason that none of the women had symptoms suggestive of mixed urinary incontinence. Also the severity of incontinence was defined only by the frequency of UI occurrence and the amount of UI was not taken into consideration.

\section{CONCLUSIONS}

The results of this study can be considered reliable, as we found significant prevalence of UI among the women we studied. There is a need to increase the awareness among clinicians as to the impact of UI onto patients' QOL. As it negatively affects their QOL, it needs to be addressed by health education programs targeting those at higher risk. In addition to promoting the women's awareness and knowledge of cure prospects consulting with a female health professional like family health worker or a public Health nurse could eliminate part of the shame barrier. Even though, it is not a common problem, more research is needed in young and middle-aged women.

Furthermore, the study itself could have a sensitizing effect on the participants (health care workers and women) result in a better knowledge of the illness and its solutions.

\section{REFERENCES}

1. Paul A, Kelleher CJ, Lindsey AK, Rebecca GR. Overactive Bladder Significantly Affects Quality of Life, The American Journal of managed care 2000 July; 6 (11):

2. Con J. Kelleher, Linda D. Cardozo, and Philip M. Toozs-Hobson. Quality of life and urinary incontinence Current Opinion in Obstetrics and Gynecology 1995; 7:404-40

3. Keller SL. Urinary incontinence: Occurrence, knowledge, and attitudes among women aged 55and older in a rural midwestern setting. J Wound Ostomy Continence Nurs 1999; 26:30-38.

4. Levy R, Muller N. Urinary incontinence: economic burden and new choices in pharmaceutical treatment. Adv Therapy July 2006; 23(4):556-573.

5. Thomas TM, Plymat KR, Blannin J, Meade TW. Prevalence of urinary incontinence. BMJ 1980; 281: 12431245

6. Bradway C, \& Barg F. Developing a cultural model for long-term femaleurinary incontinence. Social Science \& Medicine, 2006; 63:3150 3161.

7. Fultz NH, Burgio K, Diokno AC, Kinchen S., Obenchain R, Bump RC. Burden of stress urinary incontinence for community-dwelling women. American Journal of Obstetrics and Gynecology 2003; 189 (5):12751282.

8. Bradway C, \& Strumpf N. Seeking care: women's narratives concerning 
long-term urinary incontinence. Urologic Nursing 2008 ; 28: 123 129.

9. Doshani A, Pitchforth E., Mayne CJ, Tincello DG. Culturally sensitive continence care: a qualitative study among South Asian Indian women in Leicester. Family Practice 2007; 24(6) :585-593

10. Kelleher CJ, Cardozo LD, ToozsHobson PM. Quality of life and urinary incontinence. Curr Opin Obstet Gynecol. 1995; 7:404-408.

11. Kirkland VL, Palmer MH, Fitzgerald S. Incontinence in a manufacturing setting: women's Perceptions and responses. Public Health Nurs. 2001, 18: 312-317.

12. Goldstein M, Hawthorne ME, Engberg S, McDowell BJ, Burgio KL. Urinary incontinence: why people do not seek help. J Gerontol Nursing. 1992, 18: 15-20.

13. NIH Consensus Statements. Urinary incontinence in adults 1998; 71: 1-24

14. Peake S, Manderson L, Potts H. "Part and parcel of being a woman": female urinary incontinence and constructions of control. Medical
Anthropology Quarterly 1999; 13(3): 267-285.

15. Norton PA, MacDonald LD, Sedgwick PM, Stanton SL. Distress and delay associated with urinary incontinence, frequency and urgency in women. BMJ 1988; 297:11871189

16. Paul A, Kelleher C.J., Lindsey A. K, Rebecca G. R. Overactive Bladder Significantly Affects Quality of Life, The American Journal of managed care July 2000; 6 (11).

17. Grimby A, Milsom I, Molander U, Wiklund I, Eklund P. The influence of urinary incontinence on the quality of life of elderly women. Age Ageing 1993; 22: 82-29.

18. Lwanga SK, Lemeshow S. Sample size determination in health studies, A practical manual. World Health Organization. 1991:1-3

19. Martínez-Mesa J, González-Chica DA, Bastos JL, Bonamigo RR, Duquia RP. Sample size: how many participants do I need in my research?. Anais brasileiros de dermatologia. 2014 Aug; 89 (4): 609-15.
20. Hannestad YS, Rortveit G, Sandvik H, Hun- skaar S: A community-based epidemiological survey of female urinary incontinence: the Norwegian EPINCONT Study. J Clin Epidemiol 2000; 53:1150-1157.

21. Kelleher CJ, Cardozo LD, Khullar $\mathrm{V}$. A new questionnaire to assess the quality of life of urinary incontinent women, British Journal of Obstetrics and Gynaecology, December 1997; 104: 1374-1379.

22. Ko Y, Lin SJ, Salmon JW, Bron MS: The impact of urinary incontinence on quality of life of the elderly. Am J Manag Care 2005; 11(4): S103-S111.

23. Ilana M, Gabriel G, David G. Urinary Incontinence in Women under 65: Quality of Life, Stress Related to Incontinence and Patterns of Seeking Health Care.

24. Quality of Life Research Oct 2004; 13 (8): 1381-1390

25. Ozerdogan N, Kizilkaya Beji N, Yalcin O. Urinary incontinence: its prevalence, risk factors and effects on the quality of life of women living in a region of Turkey. Gynecol Obstet Invest 2004; 58:145-150. 